\title{
THE RELATIONSHIP BETWEEN HYPERGLYCEMIA STATUS AND HIGH GASTRIC RESIDUAL VOLUME STATUS IN ADULT ICU PATIENTS
}

\author{
Pittara Pansawira, ${ }^{1}$ Luciana B Sutanto, ${ }^{1}$ Dita Aditianingsih ${ }^{2}$ \\ 1 Indonesian Nutrition Association, Jakarta, Indonesia \\ 2 Department of Anesthesiology, Cipto Mangunkusumo Hospital, Jakarta, Indonesia
}

\begin{abstract}
Introduction:
Hyperglycemia commonly occurs in critically ill patients due to metabolic stress. Hyperglycemia can cause gastric motility disturbance in which can cause high gastric residual volume (GRV). The objective of this study is to determine the relationship between hyperglycemia and high GRV status in ICU patients.
\end{abstract}

Methods: This study used cross sectional method with consecutive sampling of 96 adult ICU patients. Blood glucose level were measured every 12 hours and GRV every 4 hours on first and second day admission to ICU. Data were analyzed with Statistical Package for Social Science Program (SPSS) version 20.0. The relationship between hyperglycemia status and high GRV status were analyzed using Chi-Square test.

Results: Hyperglycemia status was found in $45.8 \%$ subjects on day 1 and $35.4 \%$ on day 2 . High GRV status was found in $28.1 \%$ on day 1 and $25 \%$ on day 2. There was no significant relationship between hyperglycemia and high GRV status on day 1 and 2 $(p=0.34$ and 0.81$)$. However, in 12 subjects, we found high GRV occurred 19.67 \pm 11.06 hours after the onset of hyperglycemia.

Conclusion: There was no significant relationship between hyperglycemia status and high GRV status, but high GRV could be found later after hyperglycemia.

Keywords: critically ill patients, hyperglycemia, gastric residual volume

\section{INTRODUCTION}

Hyperglycemia commonly occurs in critically ill patients due to metabolic stress, even though without history of diabetes. ${ }^{1-3}$ The prevalence of hyperglycemia varies in many researches. Van den Berghe $e t a l^{4}$ found $12 \%$ of critically ill patients had blood glucose level $>200 \mathrm{mg} / \mathrm{dL}$. Another study by
Cely et $a l^{5}$ found $38 \%$ of critically ill patients had blood glucose level $>150 \mathrm{mg} / \mathrm{dL}$ and $23 \%$ of them had $>200 \mathrm{mg} / \mathrm{dL}$. Unfortunately, data about prevalence of hyperglycemia in critically ill patients has not been found in Indonesia yet.

Based on the Normoglycemia in Intensive Care Evaluation-Survival Using Glucose Algorithm Regulation (NICE-SUGAR), hyperglycemia in critically ill is defined by blood glucose level $>180$ $\mathrm{mg} / \mathrm{dL}{ }^{6}$ It occurs due to insulin resistance and the increase of gluconeogenesis in responds to inflammation. ${ }^{1,3}$ It can also occur due to excessive intake and corticosteroids therapy. ${ }^{1,7}$

Hyperglycemia may results in gastric motility disturbance which alter gastric emptying and, therefore, can cause high gastric residual volume. ${ }^{8,9}$ A study by Nguyen et al ${ }^{10}$ shows high gastric residual volume occurred more often in patients who had hyperglycemia. The cut off points of high gastric residual volume varies from $>150$ $\mathrm{mL}$ to $>500 \mathrm{~mL}^{11-13}$ In Intensive Care Unit of Cipto Mangunkusumo Hospital, the cut off point used is $>125 \mathrm{~mL}$ every 4 hours.

Prevalence of high gastric residual volume varies from $32-60 \% .{ }^{13,14}$ A study by Junizar ${ }^{15}$ in Cipto Mangunkusumo Hospital ICU found 23.3\% of critically ill patients had high gastric residual volume. This condition can hinder adequate enteral feeding ${ }^{14}$ and increase the risk of aspiration ${ }^{16}$ which results in increase of mortality. ${ }^{17,18}$ Other causes of high gastric residual volume are low perfusion, ${ }^{19}$ sympathetic response during metabolic stress, ${ }^{20}$ low potassium level, ${ }^{9}$ opioids and cathecolamine therapies. $^{14,21}$

There are only few studies regarding the relationship between hyperglycemia in critically ill patients and high gastric residual volume. However, there is still no research data regarding this issue in Indonesia. Therefore, this study was conducted in ICU of Cipto Mangunkusumo General Hospital, Jakarta, Indonesia. The results of this study was expected to be able to estimate the percentage of 
hyperglycemia and high gastric residual volume for additional knowledge in nutrition therapy for critically ill patients, especially in Indonesia.

\section{METHODS}

The study was done in May to August 2014 in Cipto Mangunkusumo General Hospital, Jakarta, Indonesia, and had been approved by the Ethics Committee of the Faculty of Medicine, University of Indonesia. The inclusion criteria were male and female, age 18-59 years old, had nasogastric or orogastric enteral tube applied, and consented by their family or relatives to participate in this study. Any patient who had surgical procedure involving removal of pyloric sphincter was excluded.

Data were collected within the first and second 24 hours of admission in ICU. Subjects who had earlier enteral tubes removal, left ICU (move to ward) or passed away before data collection was completed were dropped out from this study. The data was collected in the first and second 24 hours of admission in ICU to avoid large number of drop outs, loss to follow up, and too much data variation because the staying time differs greatly in this ICU.

The sample size was determined with the formula below and subject was recruited consecutively. According to formula below, minimum number of subject should be recruited was 96 patients.

$$
\mathrm{n}=\frac{\mathrm{Z}_{\alpha}^{2} \times \mathrm{PQ}}{\mathrm{d}^{2}}
$$

$\mathrm{n} \quad=$ number of subject

$\mathrm{Z} \alpha=$ cut off point for statistical significance $=1.96$, for $\alpha=0.05$

$\mathrm{P}=$ percentage of high gastric residual volume in critically ill patient with hyperglycemia. $\mathrm{P}$ was assumed to be $50 \%=0.5^{22}$

$\mathrm{Q}=1-\mathrm{P}$

$\mathrm{d}=$ acceptable drop out rate in clinical research $=10 \%$

The data collected were age, gender, weight, BMI, nutritional status, calorie intake, diagnosis, serum potassium level, MAP status, use of opioids and catecholamines from ICU medical charts. Blood glucose levels were measured by glucometer every 12 hours starting from admission until 48 hours during ICU stay. Gastric residual volume was measured every 4 hours (gastric residue was collected in an empty container and its volume was measured). All parameters measured were divided into two categories: hyperglycemia (if there was at least once blood glucose level $>180 \mathrm{mg} / \mathrm{dL}$ ) and euglycemia (if blood glucose levels were $\leq 180$ $\mathrm{mg} / \mathrm{dL}$ ); high gastric residual volume (if there was at least once gastric residual volume $>125 \mathrm{~mL}$ found) and normal (if gastric residual volume was $\leq 125 \mathrm{~mL}$ in each measurement); hypokalemia (serum potassium level was $<3.5 \mathrm{mmol} / \mathrm{L}$ measured during this study) and normo/hyperkalemia (serum potassium levels were normal or $>5.5 \mathrm{mmol} / \mathrm{L}$ ); low MAP status (if there was at least once MAP level $<65 \mathrm{mmHg}$ ) and normal MAP status (if MAP levels were $\geq 65 \mathrm{mmHg}$ ); "yes" (if any opioid medication or catecholamine was used) and "no" (if it was not used).

Data were analyzed using Statistical Package for Social Science (SPSS) version 20.0. The Kolmogorov-Smirnov test of normality was used for age, weight, BMI, and calorie intake. Numerical data that are normally distributed will be shown in mean \pm standard deviation (SD); and in median (minimum-maximum value) if otherwise. Categorical data will be shown in distribution and frequency. The relationship between hyperglycemia and high gastric residual volume were analyzed using Chi-Square test.

\section{RESULTS}

Within 10 weeks of the study, 104 subjects were collected. There were 96 subjects analyzed. There were 8 subjects who were dropped out from this study: 2 subjects had their enteral tube removed and 6 subjects passed away before 48 hours.

Baseline characteristic of the subject are shown in Table 1 and 2. Percentage of hyperglycemia and high gastric residual volume status are shown in Figure 1. Analysis of relationship between hyperglycemia and high gastric residual volume of this study is shown in Table 3. There was no significant relationship between hyperglycemia status and high gastric residual volume in the first and second 24 hours of admission. 
Tabel 1 Baseline Characteristic of The Subjects

\begin{tabular}{lc}
\hline \multicolumn{1}{c}{ Characteristic } & Results \\
\hline Age (years old) & $39(18-59)$ \\
Gender, n (\%) & \\
Male & $51(53.1 \%)$ \\
Female & $45(46.9 \%)$ \\
& \\
Weight $(\mathrm{kg})$ & $60(30-90)$ \\
BMI $\left(\mathrm{kg} / \mathrm{m}^{2}\right)$ & $23.06 \pm 4.29$ \\
Nutritional status, $\mathrm{n}(\%)$ & \\
Underweight & $13(13.5 \%)$ \\
Normoweight & $36(37.5 \%)$ \\
Preobese & $18(18.8 \%)$ \\
Obese I & $23(24 \%)$ \\
Obese II & $6(6.3 \%)$ \\
Diagnosis, n (\%) & \\
Surgical & $69(71.9 \%)$ \\
Medical & $27(28.1 \%)$ \\
\hline
\end{tabular}

Additional analysis was done to determine the possibility of time needed to develop into high gastric residual volume from the time hyperglycemia was detected. There are 12 subjects who had high gastric residual volume after hyperglycemia was detected. The analysis showed the mean time measured was $19.67 \pm 11.06$ hours. not shown). Calorie intakes were still below target recommended by ESPEN guidelines. ${ }^{29}$ Almost all subjects $(98.96 \%)$ of this study received intermittent enteral feeding with slow drips. The nutrition composition given was a standard formula complied to ESPEN guidelines. ${ }^{30}$ Therefore, calorie intakes were considered not affecting the outcomes of this study. Other factors (potassium level, the use of opioid, and catecholamine medications) also did not affect gastric residual volume in this study (data not shown).

\section{Blood Glucose Level dan Gastric Residual Volume Status}

There was a significant decrease of hyperglycemia percentage $(>10 \%)$ in second day of admission in ICU compared to first day. This could mean that hyperglycemia was promptly managed. In this ICU, management of hyperglycemia is done with strict glucose control by insulin starting from blood glucose $>180 \mathrm{mg} / \mathrm{dL}$. This cut off point is based on ASPEN Clinical Guidelines. ${ }^{31}$

The proportion of hyperglycemia in this study is lower compared to other studies by Van den Berghe et $\mathrm{al}^{4}(12 \%)$ and Cely et $\mathrm{al}^{5}(38 \%)$. This can be due to higher blood glucose cut-off point in

Tabel 2 Calorie Intake, Potassium Level Status, MAP Status, Use of Opioids and Cathecolamines on Day 1 and 2 Admission in ICU

\begin{tabular}{lcc}
\hline \multicolumn{1}{c}{ Characteristic } & Day 1 & Day 2 \\
\hline Calorie intake (kcal/kg/day) & $11.16 \pm 6.14$ & $17.45 \pm 7.18$ \\
Potassium level status, n (\%) & & \\
Hypokalemia & $29(30.2 \%)$ & $24(25.3 \%)$ \\
Normokalemia & $60(62.5 \%)$ & $65(67.7 \%)$ \\
Hyperkalemia & $7(7.3 \%)$ & $7(7.3 \%)$ \\
MAP status, n (\%) & $45(46.9 \%)$ & $24(25 \%)$ \\
Low & $51(53.1 \%)$ & $72(75 \%)$ \\
Normal & $33(34.4 \%)$ & $30(31.3 \%)$ \\
Opioids, n (\%) & $63(65.6 \%)$ & $66(68.8 \%)$ \\
Yes & & \\
No & $49(51 \%)$ & $47(49 \%)$ \\
Catecholamines, n (\%) & $47(49 \%)$ & $49(51 \%)$ \\
Yes &
\end{tabular}

\section{DISCUSSION}

According to several studies, age, ${ }^{23,24}$ gender, ${ }^{25}$ $\mathrm{BMI}^{26}$ and calorie intake ${ }^{27,28}$ may affect blood glucose level or gastric residual volume. However in this study, none of those characteristics affected blood glucose level or gastric residual volume (data both studies ( $>200 \mathrm{mg} / \mathrm{dL})$.

There was no significant decrease of subjects with high gastric residual volume status in this study. This number also does not differ significantly compared to study by Junizar et al ${ }^{15}$ $(23.3 \%)$. The number of subjects with high gastric residual volume in this study is lower compared to 
Percentage of hyperglycemia and high GRV status on day 1 and 2

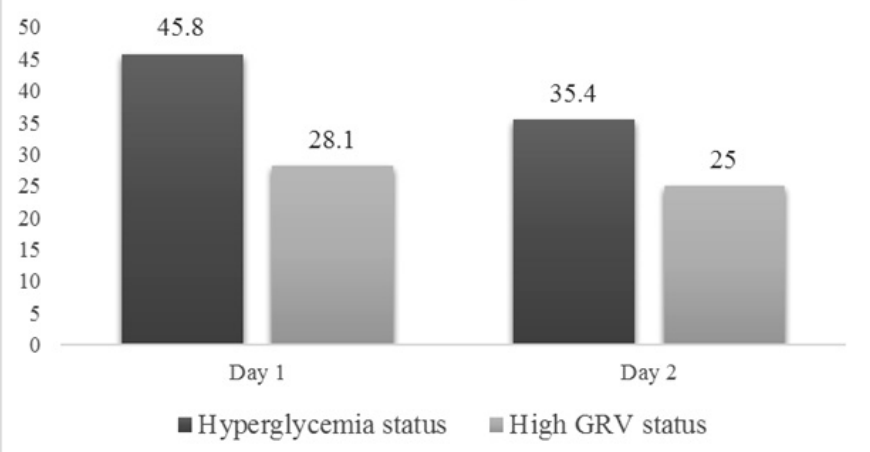

GRV: gastric residual volume

studies by Mentec et $\mathrm{al}^{14}(32 \%)$ and Metheny et $\mathrm{al}^{16}$ $(72.8 \%)$ which can be due to different cut-off point and frequency of measurement used in both studies. measured was $19.67 \pm 11.06$ hours. A study by Nguyen et al ${ }^{10}$ showed critically ill patients who are intolerant of enteral feeding had a trend for higher blood glucose levels on admission and had greater variation in blood glucose levels, especially 24 hours prior to enteral feeding intolerance. However, in this research, the analysis can not be concluded due to lack of numbers of subject. Therefore, further research with case control or longitudinal method is needed to determine this issue.

No relationship between hyperglycemia and high gastric residual volume in this study could be due to the length of study time, blood glucose level measurement frequencies and management of hyperglycemia in subjects. Longer time is probably needed to observe the effect of hyperglycemia to

Table 3 The Relationship Between Hyperglycemia Status and High Gastric Residual Volume Status

\begin{tabular}{|c|c|c|c|c|c|c|c|c|}
\hline \multirow{3}{*}{$\begin{array}{l}\text { Blood glucose level } \\
\text { status }\end{array}$} & \multicolumn{8}{|c|}{ Gastric residual volume } \\
\hline & \multicolumn{4}{|c|}{24 hours } & \multicolumn{4}{|c|}{48 hours } \\
\hline & High & Normal & Total & $\mathrm{p}$ & High & Normal & Total & $\mathrm{p}$ \\
\hline \multicolumn{9}{|l|}{24 hours } \\
\hline Hyperglycemia & 10 & 34 & 44 & 0.28 & 13 & 31 & 44 & 0.34 \\
\hline Euglycemia & 17 & 35 & 52 & & 11 & 41 & 52 & \\
\hline \multicolumn{9}{|l|}{48 hours } \\
\hline Hyperglycemia & - & - & - & - & 9 & 25 & 34 & 0.81 \\
\hline Euglycemia & - & - & - & - & 15 & 47 & 62 & \\
\hline
\end{tabular}

The relationship between hyperglycemia and high gastric residual volume

The results showed no significant relationship between hyperglycemia and high gastric residual volume in both first and second 24 hours of admission in ICU. These results were similar with a study by Mentec et $\mathrm{al}^{14}$ which found no significant difference of blood glucose level between subjects with high and normal gastric residual volume. The result of this study differs from a study by Nguyen et $\mathrm{al}^{10}$ which found high gastric residual volume was associated with hyperglycemia. The difference of the results may due to difference in the studies objectives and blood glucose measurement frequencies.

Additional analysis was done to determine the possibility of time needed to develop into high gastric residual volume from the time hyperglycemia was detected. The analysis of 12 subjects with high gastric residual volume occurred after hyperglycemia showed the mean time gastric residual volume. In this study, blood glucose level measurements done other than every 12 hours were not included in the analysis. Therefore, there were possibly more subjects who had hyperglycemia. In addition, the prompt management of hyperglycemia in this study possibly hindered the high gastric residual volume to develop. For those reasons, further research using case control or longitudinal method is needed. Using more frequent blood glucose level measurements or continuous blood glucose monitoring is suggested in further research.

There are limitations to this study. This study did not examine disease severity and more specific diagnosis of the subjects in which would possibly affect gastric emptying rate. Data were only collected within two days, therefore it may be too short to observe the effect of hyperglycemia to gastric residual volume. Blood glucose level was measured every 12 hours, therefore any hyperglycemia occurred beyond those time could be missed. The design of this study could also become 
a limitation. We used cross sectional study, whose data was divided categorically, to determine the relationship because high gastric residual volume was expected to happen concurrently with hyperglycemia onset or after hyperglycemia occurred. Diabetic patients were not excluded, which could also affect the outcome of this study. Gastric emptying disorder frequently occurs in patients with chronic diabetes mellitus.

In conclusion, there was no significant relationship between hyperglycemia status and high gastric residual status in this study. Further research with more frequencies of blood glucose measurements or using continuous blood glucose monitoring is needed to better determine the hyperglycemia status in critically ill patients. Further research is also needed to determine whether episodic or chronic hyperglycemia can cause high gastric residual volume much later, and also observation on the average time from the beginning of hyperglycemia to develop into high gastric residual volume is needed.

\section{Conflicts of Interest}

Authors declared no conflict of interest regarding this study.

\section{Acknowledgment}

We would like to acknowledge all ICU staff of Cipto Mangunkusumo General Hospital who had helped this study.

\section{REFERENCES}

1. Mizock BA. Alterations in fuel metabolism in critical illness: Hyperglycaemia. Best Pract Res Clin Endocrinol Metab 2001;15:533-51.

2. McCowen KC, Malhotra A, Bistrian BR. Stress-induced hyperglycemia. Crit Care Clin 2001;17:107-24.

3. Hsu C. Glycemic control in critically ill patients. World J Crit Care Med 2012;1:31-9.

4. Van den Berghe G, Wouters P, Weekers F, Verwaest C, Bruyninckx F, Schetz M, et al. Intensive insulin therapy in critically ill patients. N Engl J Med 2001;345:1359-67.

5. Cely C, Arora P, Quartin A, Kett D, Schlein R. Relationship of baseline glucose homeostasis to hyperglycemia during medical critical illness. Chest 2004;126:879-87.

6. Van den Berghe G, Schetz M, Vlasselaers D, Hermans G, Wilmer A, Bouillon $\mathrm{R}$, et al. Intensive insulin therapy in critically ill patients: NICE-SUGAR or Leuven blood glucose target? J Clin Endocrinol Metab 2009;94:3163-70.

7. Powers A. Diabetes mellitus. In: Fauci A, Braunwald E, Kasper D, Hauser S, Longo D, Jameson J, et al., editors. Harrison's Principles of Internal Medicine 17th ed. McGrawHill 2008. p. 2528-35.
8. Zhou S, Lu Y, Owyang C. Gastric relaxation induced by hyperglycemia is mediated by vagal afferent pathways in the rat. AJP Gastrointest Liver Physiol. 2008;294:1158-64.

9. Ukleja A. Altered GI motility in critically ill patients: current understanding of pathophysiology, clinical impact, and diagnostic approach. Nutr Clin Pract 2010;25:16-25.

10. Nguyen N, Ching K, Fraser R, Chapman M, Holloway R. The relationship between blood glucose control and intolerance to enteral feeding during critical illness. Intensive Care Med 2007;33:2085-92.

11. Pinilla J, Samphire J, Arnold C, Liu L, Thiessen B. Comparison of gastrointestinal tolerance to two enteral feeding protocols in critically ill patients: a prospective, randomized controlled trial. $J$ Parenter Enter Nutr 2001;25:81-6.

12. Landzinski J, Kiser TH, Fish DN, Wischmeyer PE, MacLaren R. Gastric motility function in critically ill patients tolerant vs intolerant to gastric nutrition. $J$ Parenter Enter Nutr 2008;32:45-50.

13. Montejo JC, Miñambres E, Bordejé L, Mesejo A, Acosta $\mathrm{J}$, Heras A, et al. Gastric residual volume during enteral nutrition in ICU patients: the REGANE study. Intensive Care Med 2010;36:1386-93.

14. Mentec H, Dupont H, Bocchetti M, Cani P, Ponche F, Bleichner G. Upper digestive intolerance during enteral nutrition in critically ill patients: frequency, risk factors, and complications. Crit Care Med 2001;29:1955-61.

15. Junizar J. Mean arterial pressure dan hubungannya dengan status volume residu lambung pada pasien sakit kritis yang mendapatkan nutrisi enteral. [Jakarta]: Universitas Indonesia; 2013.

16. Metheny NA, Schallom L, Oliver D, Clouse R. Gastric residual volume and aspiration in critically ill patients receiving gastric feedings. Am J Crit Care 2008;17(6):512-20. 17. Btaiche IF, Chan L, Pleva M, Kraft MD. Critical illness, gastrointestinal complications, and medication therapy during enteral feeding in critically ill adult patients. Nutr Clin Pract 2010;25:32-49.

18. Martindale R, McClave S, Vanek V, McCarthy M, Roberts P, Taylor B, et al. Guidelines for the provision and assessment of nutrition support therapy in the adult critically ill patient: Society of Critical Care Medicine and American Society for Parenteral and Enteral Nutrition. Crit Care Med 2009;37:1-30.

19. Spain DA. When is the seriously ill patient ready to be fed? J Parenter Enter Nutr 2002;26:62-8.

20. Chapman MJ, Nguyen NQ, Deane AM. Gastrointestinal dysmotility: clinical consequences and management of the critically ill patient. Gastroenterol Clin North Am 2011;40:725-39.

21. Sternini C, Patierno S, Selmer I, Kirchgessner A. The opioid system in the gastrointestinal tract. Neurogastroenterol Motil 2004;16:3-16.

22. Madiyono B, Moeslichan S, Sastroasmoro S, Budiman I, Purwanto S. Bab 17 Perkiraan besar sampel. In: Sastroasmoro S, Ismael S, editors. Dasar-dasar Metodologi Penelitian Klinis. Edisi ke-4. Sagung Seto, Jakarta; 2011. p. 348-82.

23. Di Francesco V, Zamboni M, Dioli A, Zoico E, Mazzali G, Omizzolo F, et al. Delayed postprandial gastric emptying and impaired gallbladder contraction together with elevated 
cholecystokinin and peptide YY serum levels sustain satiety and inhibit hunger in healthy elderly persons. $J$ Gerontol A Biol Sci Med Sci 2005;60:1581-5.

24. Bando Y, Ushiogi Y, Okafuji K, Toya D, Tanaka N, Fujisawa M. The relationship of fasting plasma glucose values and other variables to 2 -h postload plasma glucose in japanese subjects. Diabetes Care 2001;24:1156-60.

25. Jones K, Russo A, Stevens J, Wishart J, Berry M, Horowitz M. Predictors of delayed gastric emptying in diabetes. Diabetes Care 2001;24:1264-9.

26. Xu F, Wang Y, Lu L, Liang Y, Wang Z, Hong X, et al. Comparison of anthropometric indices of obesity in predicting subsequent risk of hyperglycemia among Chinese men and women in Mainland China. Asia Pac $J$ Clin Nutr 2010;19:586-93.

27. Gallagher M. Chapter 3: The nutrients and their metabolism. In: Mahan L, Escott-Stump S, editors. Krause's Food and Nutrition Therapy. 13th ed. Missouri: Saunders Elsevier; 2012. p. 52-3.

28. Steevens EC, Lipscomb AF, Poole GV, Sacks GS. Comparison of continuous vs intermittent nasogastric enteral feeding in trauma patients: perceptions and practice. Nutr Clin Pract 2002;17:118-22.

29. Kreymann KG, Berger MM, Deutz NEP, Hiesmayr M, Jolliet P, Kazandjiev G, et al. ESPEN guidelines on enteral nutrition: intensive care. Clin Nutr 2006;25:210-23.

30. Lochs H, Allison SP, Meier R, Pirlich M, Kondrup J, Schneider S, et al. Introductory to the ESPEN guidelines on enteral nutrition: terminology, definitions and general topics. Clin Nutr 2006;25:180-6.

31. McMahon MM, Nystrom E, Braunschweig C, Miles J, Compher C, the American Society for Parenteral and Enteral Nutrition (A.S.P.E.N.) Board of Directors. A.S.P.E.N. clinical guidelines: nutrition support of adult patients with hyperglycemia. J Parenter Enter Nutr 2012;37(1):23-36.

32. Hsu C, Sun S, Lee D, Lin S, Wong K, Huang H, et al. Impact of disease severity on gastric residual volume in critical patients. World J Gastroenterol 2011;17:2007-12.

33. Nguyen NQ, Ng M, Chapman M, Fraser RJ, Holloway R. The impact of admission diagnosis on gastric emptying in critically ill patients. Crit Care 2007;11:16-27. 